\title{
Investigating Effects of Task Structure on EFL Learner's Oral Performance
}

\author{
Massoud Rahimpour (Corresponding author) \\ The University of Tabriz and the University of Queensland \\ E-mail: rahimpour2003@yahoo.com
}

Faezeh mehrang

English Department, Faculty of Persian Literature and Foreign Languages

The University of Tabriz

E-mail: f_mehrang@yahoo.com

\begin{abstract}
It is argued that tasks with different structures yield different performances in terms of accuracy, fluency and complexity. The present study is thus an attempt to investigate the impact of task structure on second language task performance. Thirty two upper-intermediate Iranian learners of English performed two narrative tasks (Structured vs. Unstructured) based on cartoon scripts. The performances, then, were recorded, transcribed and coded to measure the accuracy, fluency and complexity of the participants' performances. Next, the paired samples t-test was employed to analyze the collected data. The results of the statistical analysis revealed that task structure had no effect on the accuracy, fluency and complexity of performance. Findings have pedagogical implications in the area of syllabus design.
\end{abstract}

Keywords: Task-based language teaching, Task structure, Accuracy, Fluency, Complexity

\section{Introduction}

Over the past decades, there has been an attempt to find out the role of "task" in second and foreign language teaching and learning (Bygate, 2001; Gilabert, 2005, 2007; Ortega, 1995, 2005; Rahimpour, 2007, 2008; Robinson, 2005). Task-based language teaching takes task as its unit of analysis and emphasizes the creation of meaning without any prior prescription of forms. Therefore, learners are free to use any strategies or forms to perform the task and achieve the task goal (Willis and Willis, 2001).

Research into task-based language teaching is mainly conducted because of dealing with the problem of determining the relevant grading and sequencing criteria for designing and classifying tasks for task-based syllabi (Long and Crookes, 1992; Robinson, 2003, 2006) and has mostly focused on investigating the effects of task design and task characteristics on task performance (Foster and Skehan, 1996; Skehan and Foster, 1997, 1999; Tavakoli and Foster, 2008; Tavakoli and Skehan, 2005).

Skehan (2003) points out that a task can have the following characteristics all of which have an impact on task performance in terms if accuracy, fluency and complexity.

Table 1. Task characteristics and influence upon performance in Skehan (2003)

Among the above characteristics, task structure is the one which has not been fully investigated. As a consequence, the present paper investigates the effect of task structure on task performance.

\section{Task Structure}

The variable which was investigated in the present paper was inherent task structure. Studies examining the effect of task structure on oral performance include Skehan and Foster (1999), Tavakoli and Skehan (2005), Tavakoli and Foster (2008), Tavakoli (2009). In general, findings of these studies revealed that task structure resulted in more accurate and fluent performance while leaving complexity unaffected.

Task structure has been defined and operationalised in the literature by emphasizing characteristics such as a clear time line, a script, a story with a beginning, middle and end, an appeal to what is organized and familiar in the speaker's mind, and finally, the presence of a problem solution structure (Tavakoli and Skehan, 2005). In the present study, also, task structure was defined in terms of a problem-solution structure and a schematic sequential organization. Structured task was the one containing a problem-solution structure in which the events could not be reordered without compromising the story, while unstructured task was the one without a problem-solution structure and its events could be easily rearranged without losing coherence. 


\section{Cognitive Approaches to Language Learning}

There exist two conflicting theories regarding how human mind works while performing a task. The first and the widely accepted approach is Skehan's (1998) cognitive approach in which he distinguishes between an exemplar-based and a rule-based system. Skehan emphasizes that the exemplar-based system includes discrete lexical items as well as ready-made formulaic chunks of language, while the rule-based system is made up of abstract representations of the underlying patterns of the language.

Another point Skehan (1998) proposes is that language production is distinguished by three dimensions: Fluency, accuracy, and complexity. Skehan (1998) argues that to produce a fluent language, language users should access their exemplar-based and lexical systems. On the other hand, when more accuracy or complexity is needed and fluency is not of importance, performers must draw on their rule-based system and involve in more syntactic processing. Skehan (2001) also believes that humans have limited attentional resources and trade-offs always occur between fluency, accuracy and complexity and it is not possible to achieve these aspects of performance simultaneously when one is using language. In other words, if language users, for example, focus on producing a more fluent language and drawing on their exemplar-based system, their production will be less accurate and less complex. Therefore, they must prioritize where to allocate their attention.

The next theory proposed by Robinson (2001) is not in line with Skehan's (1998b) predictions. Robinson (2001) drawing on more recent work in psychology (Neumann, 1996), concluded that human attention is not limited, and that learners are able to attend to more than one aspect of language simultaneously. According to this view, the structural and functional complexities are connected rather than competing with each other.

\section{The Study}

The present research seeks to investigate the effect of task structure on EFL learner's task performanceby proposing the following research question:

\subsection{Research question}

What is the effect of task structure on the accuracy, fluency and complexity of task performance?

Based on the literature in the previous section it is hypothesized that:

\subsection{Research hypothesis}

Structured tasks will lead to more fluent and more accurate performance, while complexity will remain unaffected.

\subsection{Participants}

Participants of the study were 32 EFL learners (13 males and 19 females) studying English at a language institute in Tabriz, Iran, and were aged between 14 and 50. They were studying English as a foreign language at an upper-intermediate level and had been studying English for at least 2 years. The participants were from Azari and Persian language backgrounds and all had taken classes in which speaking and listening activities were common and they were not allowed to use Persian. The only contact they had with English outside the classroom was at school or university.

\subsection{Tasks}

Among different types of pedagogic tasks, narrative tasks are the most frequent ones referred to in the literature (Foster and Skehan, 1996; Skehan and Foster, 1999; Tavakoli and Skehan, 2005; Tavakoli and Foster, 2008). Narrative tasks as stated by Tavakoli and Skehan (2005) "refer to those stories based on a sequenced set of picture prompts which are given to participants to elicit language performance".

A lot of sources including course books and supplementary materials for teaching English and pictorial stories were examined in detail to find picture series appropriate for the study. Attempts were made to find those picture narratives which were clear enough and had a suitable length, weren't too challenging for the learners at upper-intermediate proficiency level, and were culturally familiar for the participants. At the next stage, the identified tasks were categorized into structured and unstructured. As discussed earlier (see section 2), structured tasks were the ones which had a problem-solution and a schematic sequential structure in which the events could not be reordered without compromising the story. As a result of this analysis, the signature task with a problem-solution and a sequential structure was selected as the structured task for data collection purposes (see Appendix A).

On the contrary, unstructured tasks were identified according to the lack of sequential structure in which events could easily be reordered without the story being compromised. Consequently, the birthday task (see Appendix B) was selected as the unstructured task of the study since it lacked any problem-solution structure on one hand, and any sequential structure on the other (Tavakoli and Skehan, 2005). 
Both tasks consisted of six pictures.

\subsection{Setting and Procedures}

In the current study, task structure was a within-participant variable, that is, all of the participants performed both tasks (structured and unstructured). As a consequence, to avoid a practice effect, a counter balanced design was used. In effect, participants performed both tasks in two different sequences (Tavakoli and Skehan, 2005). Table 2 demonstrates the two sequences of tasks in the study.

Table 2. Counterbalanced sequence of the tasks

To collect data, each participant came out of the class individually and went to a separate room with the researcher. The necessary instruction to do the tasks was given to the participants. They were told that they would be recorded while retelling stories in English from cartoon prompts. Moreover, it was emphasized that the recordings would be anonymous, and that this was not a test. They were allowed to quit if they weren't willing to participate. All this information was given in Persian.

After that, each participant was required to narrate each of the tasks in turn. They were given just 30 seconds to look at the pictures before they started narration. Meanwhile, the researcher provided them with any new vocabulary they might have needed. Then, the participants had the picture series in hand, and told the story to the researcher while looking at them. Moreover, they were asked to narrate each task in 2 to 3 minutes. Meanwhile, the researcher recorded the story using the CREATIVE mp3 player (DAP FLOO28) and SONY ERICSSON mobile phone (W580i). Both gadgets were used at the same time to avoid the probable loss of data. The same process was repeated for the second task.

\subsection{Measures}

Different researchers propose different ways to measure accuracy, fluency and complexity of oral performance. In the following section, we refer to the measures that were employed in the current study.

\subsubsection{Accuracy Measure (Error-free T-units)}

All the main clauses plus subordinate clauses attached to or embedded in them were counted as T-units. Only those T-units that contained no grammatical, syntactic, lexical, or spelling errors were counted as error-free T-units.

To measure accuracy, the number of error free T-units is divided by the total number of t-units (Arent, 2003; Storch, 2009)

\subsubsection{Fluency Measure (Number of Words per Minute)}

Fluency was achieved by calculating the number of words per minute (Skehan and Foster, 1999).

\subsubsection{Complexity Measure (Lexical Density)}

The number of lexical, or 'open class', words in a text (full verbs, nouns, adjectives and adverbs ending in -ly) divided by total words multiplied by 100 (Rahimpour, 1997, 1999, 2008).

\section{Results}

As mentioned in section 4.6, the number of error-free T-units was divided by the total number of T-units to measure 'accuracy' (Arent, 2003; Storch, 2009), while 'complexity' was measured by dividing the number of lexical words by the total number of words multiplied by 100 (Rahimpour, 1997, 1999, 2008), and 'Fluency' was achieved by calculating the number of words per minute (Skehan and Foster, 1999). The raw scores of the participants were, then, fed into the computer software SPSS for further data analysis. Next, the paired-samples t-test was adopted to test the hypothesis of the study and find out the way task structure affects task performance.

Table 3. Paired samples test to compare the performances in structured $v s$. unstructured tasks

The results of the statistical analysis, which are presented in table 3, revealed that there was not a statistically significant difference between the performances in the structured task compared to the unstructured task $(.202>.05, .290>.05, .107>.05)$. Therefore, the hypothesis of the study stating that "structured tasks will lead to more fluent and more accurate performance, while complexity will remain unaffected." is only proved regarding complexity. According to table 3, the mean of the accuracy of the performances in the structured task is less than that of the unstructured one $(\bar{x}: .3141<.3784)$. However, for fluency and complexity, the mean of the structured task performances is more than that of the unstructured one $(\bar{x}: 89.5613>87.0497 ; \bar{x}: 39.2750>$ 37.8237). That is, the language produced as result of performing the structured task was more fluent and more complex, but this gain was not big enough to be justified statistically. These mean differences in the rate of accuracy, fluency and complexity are clearly delineated in figures 1,2 and 3. 
Figure1. Mean Differences in the Rate of Accuracy Between Structured vs. Unstructured Tasks

Figure 1 displays the amount of the difference in the rate of accuracy for structured vs. unstructured tasks. As the figure shows, the mean of the accuracy of the performance is greater for the unstructured task which isn't in line with the predictions made earlier in this study. In other words, the structured task performance is less accurate than the performance produced through the unstructured task, while it was hypothesized that the structured task would lead to a more accurate performance.

\section{Figure 2. Mean Differences in the Rate of Fluency Between Structured vs. Unstructured Tasks}

The above figure focuses on the amount of the difference in the rate of the fluency for structured vs. unstructured tasks. As the figure shows, structured task fluency is greater than the unstructured fluency which is in line with the hypothesis of the study. However, it should be noted that this gain is not so big to be statistically significant.

Figure 3. Mean Differences in the Rate of Complexity between Structured vs. Unstructured Tasks

Figure 3 delineates the mean differences in the rate of the complexity between structured vs. unstructured tasks. According to this figure, the mean of the complexity of the performances of the structured task is more than that of the unstructured task. This gain in complexity is not big enough to be justified statistically which proves the hypothesis of the study regarding complexity.

\section{Discussions}

\subsection{Accuracy}

Like Skehan and Foster (1999), the present study found no impact of task structure on the accuracy of performance. Although many researchers (Tavakoli and Skehan, 2005; Tavakoli and Foster, 2008, Tavakoli, 2009) reported that task structure facilitates accuracy by devoting more attentional resources to it, Skehan and Foster (1999) found out that accuracy of the performance is affected by task structure only if learners have the opportunity to engage in some kind of pre-task activity prior to task performance. As a result, it can be concluded that task structure had no effect on the accuracy of the performance in the current study because the participants were not involved in any kind of pre-task activities before they performed the tasks.

\subsection{Fluency}

Unlike the research by Foster and Skehan, 1996, 1997; Skehan and Foster, 1999; Tavakoli and Skehan, 2005, the results of this study indicated that the fluency of the performance is not affected by task structure. However, this finding is in line with the results found by Tavakoli and Foster (2008) who reported that task structure had no impact on the fluency of the language production. Tavakoli and Foster (2008) explained this finding by proposing that "a monologic task makes greater demands on attentional resources than an interactive task". That is, "a very long turn, such as a monologue, gives no breathing space for on-line planning as can be snatched while listening to an interlocutor and therefore, planning has to be done while speaking or at moments of not speaking (i.e. pausing). If the attentional load gets too great, pausing has to increase in order to allow, for example, the formulator to catch up with what the conceptualizer has been feeding in".

\subsection{Complexity}

Reported findings confirmed the hypothesis of the study regarding complexity. That is, task structure had no impact on the complexity of language production which is in line with the findings of the research by Skehan and Foster (1999) and Tavakoli and Foster (2008).

\section{Pedagogical Implications}

As mentioned earlier, one of the major issues regarding task-based language teaching and learning is to find out how learners allocate attention between the competing goals of fluency, accuracy and complexity and therefore, establish a balance between these performance areas. So, the findings make it possible for a teacher or more importantly for a syllabus designer to design sequences of instructional activities that alternate attention to each of the areas so that the goal of balanced development can be obtained.

Furthermore, the major problem that task-based language teaching suffers from is determining criteria for grading and sequencing tasks (Long and Crookes, 1992; Robinson, 2003, 2006). To solve this problem, Robinson (2003, 2006) argues that empirical research should be conducted to find out the factors affecting task difficulty. Thus, the results of the present study can be used as an empirical basis to select, grade and sequence tasks within task-based syllabi and testing.

\section{References}

Arent, R. (2003). Promoting revision and development in L2 writing through a combination-based curriculum. The 
Korean TESOL Journal, 6(1), 1 - 26.

Bygate, M. (2001). Effects of task repetition on the structure and control of language. In M. Bygate, P. Skehan, and M. Swain (Ed.), Researching pedagogic tasks: Second language learning, teaching and testing (pp. 23 - 48). London: Longman.

Bygate, M., Skehan, P., \& Swain, M. (2001). Researching pedagogic tasks: Second language learning, teaching and testing. Essex: Pearson Education Limited.

Ellis, R. (2005). Planning and task performance in a second language. Amsterdam: Benjamins.

Foster, P., \& Skehan, P. (1996). The influence of source of planning and focus of planning on task-based performance. Language Teaching Research, 3/3, 215 - 247.

Gilabert, R. (2005). Task complexity and L2 narrative oral production. Unpublished Ph.D. dissertation, Barcelona, The University of Barcelona, Spain.

Gilabert, R. (2007). Effects of manipulating task complexity on self-repairs during L2 oral production. International Review of Applied Linguistics in Language Teaching (IRAL), 45/3, 215 - 240.

Long, M. H., and Crookes, G. (1992). Three approaches to task-based syllabus design. TESOL Quarterly, 26/1, 27 55 .

Neumann, O. (1996). Theories of attention. In O. Neumann and A. Sanders (Eds.), Handbook of perception and action: Vol. 3. Attention (pp. 389 - 446). San Diego: Academic Press.

Ortega, L. (1995). The effect of planning in L2 Spanish oral narratives. Studies in Second Language Acquisition, 21, $108-148$.

Ortega, L. (2005). What do learners plan? Learner-driven attention to form during pre-task planning. In R. Ellis (Ed.), planning and task performance in a second language (pp. 77 - 111). Amsterdam: Benjamins.

Rahimpour, M. (1997). Task complexity, task condition, and variation in L2 oral discourse. Unpublished PhD thesis, The University of Queensland, Australia.

Rahimpour, M. (1999). Task complexity and variation in interlanguage. In N.Jungheim \& P. Robinson (Eds.), Pragmatics and pedagogy: Proceedings of The $3^{\text {rd }}$ Pacific Second Language Research Forum, Vol 2, (pp.115-134)Tokyo:PacSLRF.

Rahimpour, M. (2001). The acquisition of L2 in instructed and naturalistic settings. Journal of the Faculty of Letters and Humanities. Tabriz University. 1-2, $9-33$.

Rahimpour, M. (2002). Factors affecting task difficulty. Journal of the Faculty of Letters and Humanities. 9/33, 1 16.

Rahimpour, M. (2003). The implementation of task-based approaches to language teaching. Paper presented at IELTL, May 21 - 22, Tehran University, Tehran.

Rahimpour, M. (2007). Task complexity and variation in L2 learner's oral discourse. Linguistics Working Papers, The University of Queensland, Brisbane, Australia.

Rahimpour, M. (2008). Implementation of task-based approaches to language teaching. Foreign Language Research, 41, Special Issue, $45-61$.

Robinson, P. (2001). Task complexity, cognitive resources, and syllabus design: A triadic framework for examining task influences on SLA. In P. Robinson (Ed.), Cognition and second language instruction (pp. 287 - 318). Cambridge: Cambridge University Press.

Robinson, P. (2003). The cognition hypothesis, task design, and adult task-based language learning. Second Language Studies, 21/2, 45 - 105.

Robinson, P. (2005). Cognitive complexity and task sequencing: Studies in a componential framework for second language task design. International Review of Applied Linguistics in Language Teaching (IRAL), 43/1, 1 - 32 .

Robinson, P. (2006). Criteria for classifying and sequencing pedagogic tasks. In M. P. G. Mayo (Ed.), Investigating tasks in formal language learning, (pp. 7 -26). Clevdon: Multilingual Matters.

Skehan, p. (1998). A cognitive approach to language learning. Oxford: Oxford University Press.

Skehan, P. (2001). Tasks and language performance assessment. In M. Bygate, P. Skehan, and M. Swain (Eds.), Researching pedagogic tasks: Second language learning, teaching and testing (pp. 167 - 185). London: Longman. 
Skehan, P. (2003). Task-based instruction. Language Teaching, 36/ Review Article, 1 - 14.

Skehan, P., and Foster, P. (1997). Task type and task processing conditions as influence on foreign language performance. Language Teaching Research, 1, 185 - 211.

Skehan, P., and Foster, P. (1999). The influence of task structure and processing conditions on narrative retellings. Language Learning, 49/1, 93 - 120.

Storch, N. (2009). The impact of studying in a second language medium university and the development of L2 writing. Journal of Second Language Writing, 8, 103 - 118.

Tavakoli, P. (2009). Assessing L2 task performance: Understanding effects of task design. System, 37,482 - 495.

Tavakoli, p., and Skehan, P. (2005). Strategic planning, task structure, and performance testing. In R. Ellis (Ed.), Planning and task performance in a second language (pp. 239 - 277). Amsterdam: Benjamins.

Tavakoli, P., and Foster, P. (2008). Task design and second language performance: The effect of narrative type on learner output. Language Learning, 58/2, 439 - 473.

Willis, D., and Willis, J. (2001). Task-based language learning. In R. Carter and D. Nunan (Eds.), The Cambridge guide to teaching English to speakers of other languages (pp. 173 - 179). Cambridge: Cambridge University Press.

\section{Appendix A}

You have thirty seconds to look at the following pictures and narrate the story they indicate in two to three minutes.
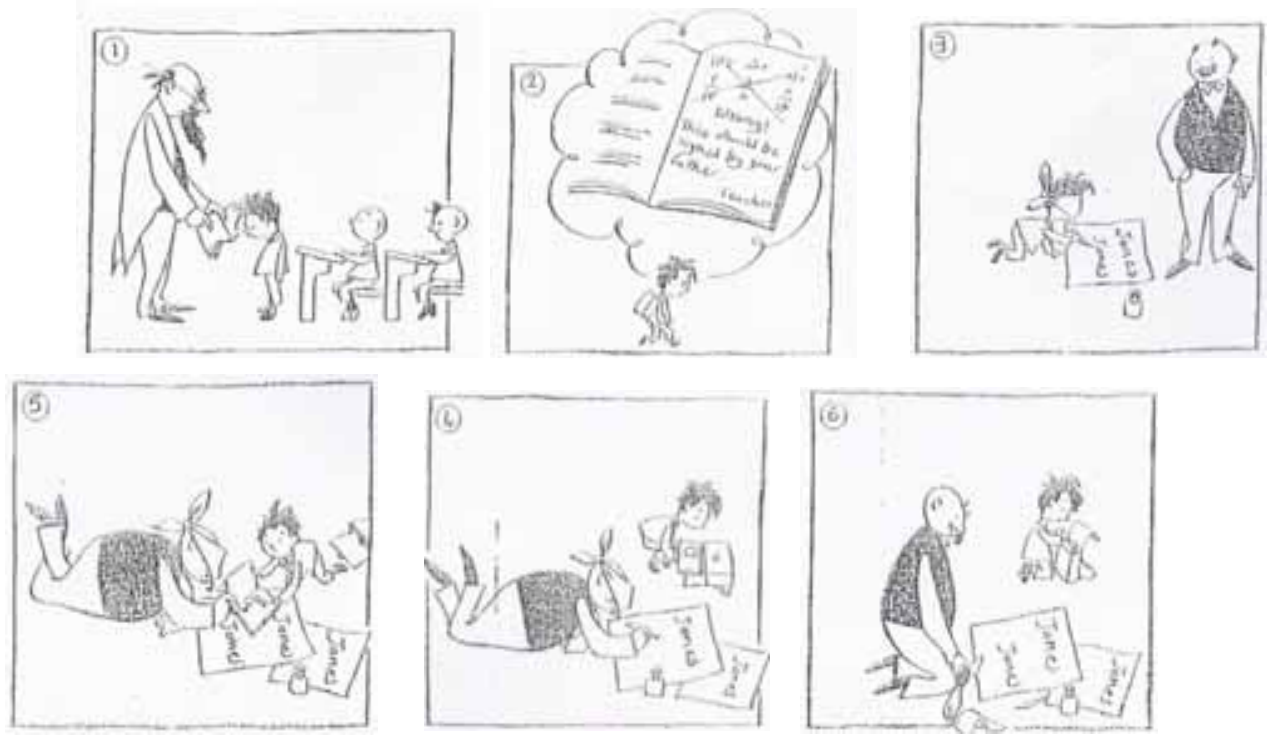

Figure 1. Signature task (structured task)

Start like this:

Sam made a lot of mistakes while doing his homework. So, his teacher asked him to ... 


\section{Appendix B}

You have thirty seconds to look at the following pictures and narrate the story they indicate in two to three minutes.
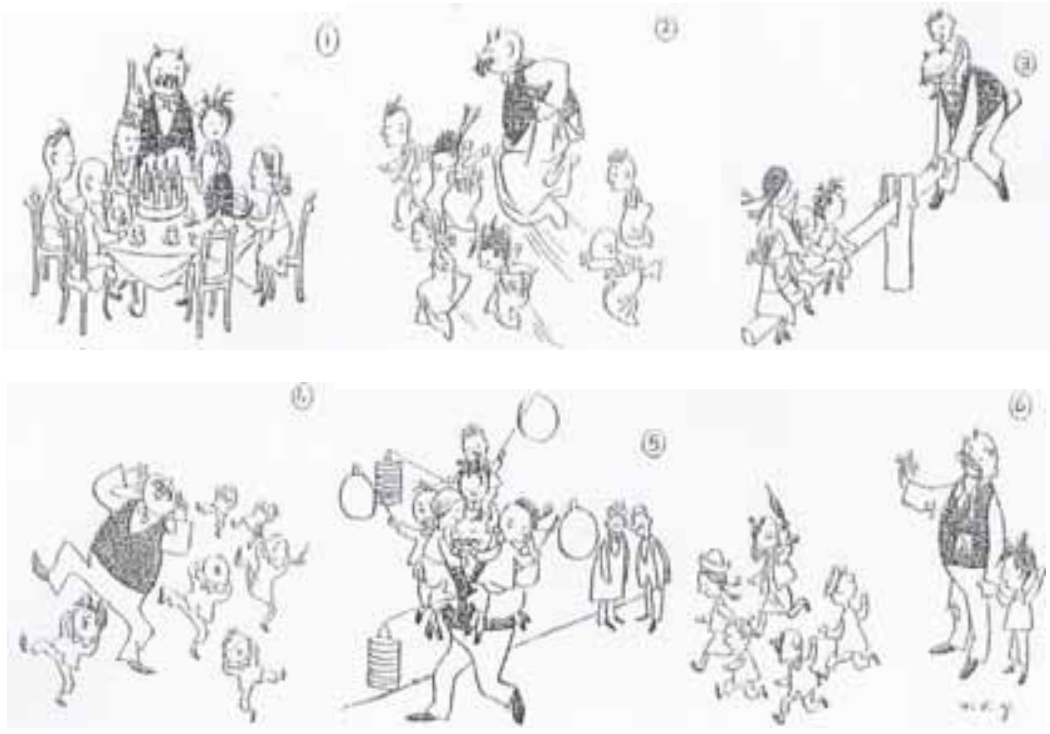

Figure 5. Birthday task (unstructured task)

Start like this:

It was Sam's birthday and his father had decided to ...

Table 1. Task characteristics and influence upon performance in Skehan (2003)

\begin{tabular}{|l|l|}
\hline Task characteristics & Influence upon performance and Research basis \\
\hline $\begin{array}{l}\text { Structured tasks, i.e. clear time line or } \\
\text { macro-structure }\end{array}$ & $\begin{array}{l}\text { Clearly greater fluency, tendency towards greater accuracy (Foster and Skehan, 1996; } \\
\text { Skehan and Foster, 1997, 1999) }\end{array}$ \\
\hline Familiar information & greater fluency and greater accuracy (Foster \& Skehan, 1996, Skehan \& Foster, 1997) \\
\hline Outcomes requiring justifications & justifications lead to markedly greater complexity of language (Skehan \& Foster, 1997) \\
\hline Interactive $v s$. monologic tasks & $\begin{array}{l}\text { Interactive tasks produce markedly more accuracy and complexity, monologic tasks } \\
\text { more fluency (Foster \& Skehan, 1996, 1999; Skehan \& Foster, 1997, 1997). }\end{array}$ \\
\hline
\end{tabular}

Table 2. Counterbalanced sequence of the tasks

\begin{tabular}{|l|l|l|}
\hline Sequence 1 & birthday & signature \\
\hline Sequence 2 & signature & birthday \\
\hline
\end{tabular}

Table 3. Paired samples test to compare the performances in structured $v s$. unstructured tasks

\begin{tabular}{|ll|r|r|r|}
\hline Measure & Structure & Mean & Std. Deviation & Sig. (2-tailed) \\
\hline Accuracy & Unstructured & .3784 & .21221 & .202 \\
& Structured & .3141 & .21822 & .290 \\
\hline Fluency & Unstructured & 87.0497 & 18.41859 & .107 \\
& Structured & 89.5613 & 19.20379 & \\
\hline \multirow{2}{*}{ Complexity } & Unstructured & 37.8237 & 3.57900 & 4.66352 \\
& Structured & 39.2750 & \\
\hline
\end{tabular}




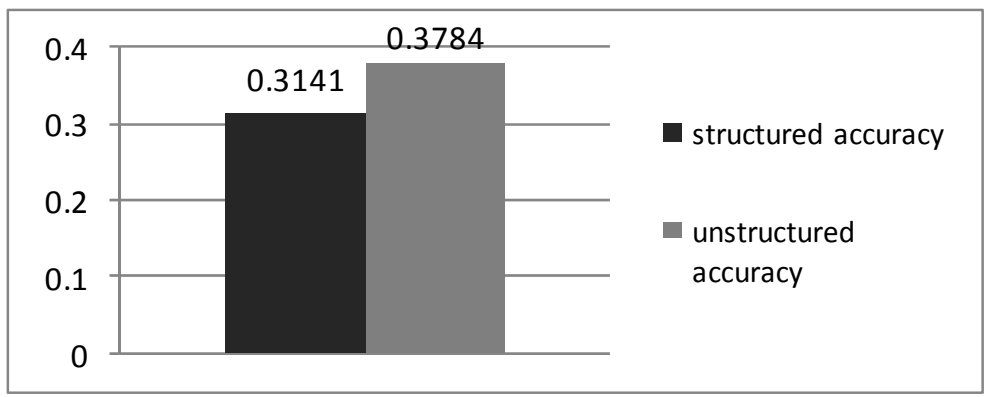

Figure1. Mean Differences in the Rate of Accuracy Between Structured vs. Unstructured Tasks

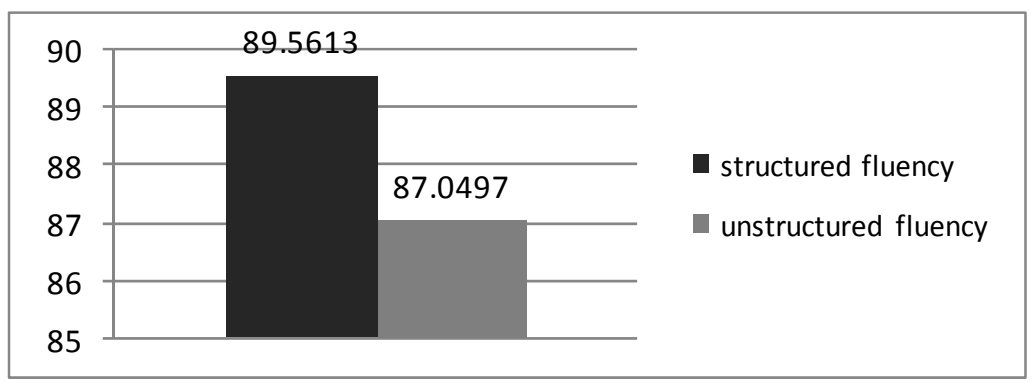

Figure 2. Mean Differences in the Rate of Fluency Between Structured vs. Unstructured Tasks

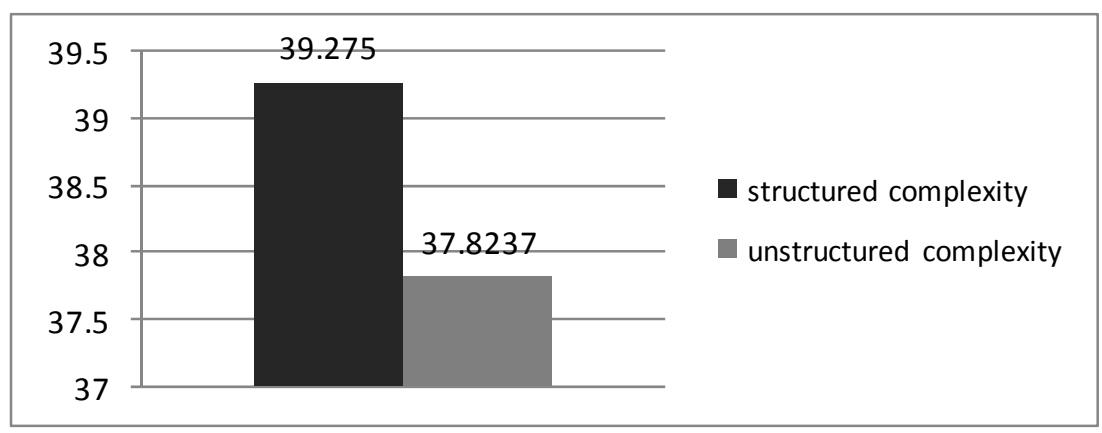

Figure 3. Mean Differences in the Rate of Complexity between Structured vs. Unstructured Tasks 